\title{
THE EFFECT OF THE POSITIVE PSYCHOLOGY INTERACTION GROUP PROGRAM ON ANGER AND HOPE IN ELDERLY INDIVIDUALS
}

Turkish Journal of Geriatrics

DOI: 10.31086/tigeri.2021.204

2021; 24(1): 95-103

- Zeynep GÜMÜŞ DEMiR ${ }^{1}$

- Remziye KESKIN ${ }^{1}$

- Kahraman GÜLER ${ }^{2}$

CORRESPONDANCE

\section{${ }^{1}$ Zeynep GÜMÜŞ DEMiR}

Üsküdar University, Psychology, Istanbul, Turkey

\section{Phone: +902164002222}

e-mail: zeynep.gumus@uskudar.edu.tr

Received: Dec 24, 2020

Accepted: Mar 08, 2021

1 Üsküdar Unıversity, Psychology, İstanbul, Turkey

2 Istanbul Aydın University, Psychology, İstanbul, Turkey

\section{Abstract}

Introduction: With the rapidly aging global population, successful and healthy aging have become important issues. The aim of this study was to examine the effect of the Positive Psychology Interaction Group Program on the anger and hope levels of elderly individuals.

Materials and Method: An experimental design with pretest-posttest control groups was used with the Positive Psychology Interaction Group Program as the independent variable, and anger and hope levels of the elderly as the dependent variables. The sample comprised 32 elderly individuals living in Darülaceze in Istanbul. Face-to-face interviews using the Sociodemographic Information Form were used to gather the participants' sociodemographic information. Hope and anger levels were evaluated using the Continuous Hope Scale (SAS) and the State Trait Anger Scale, respectively. A five-week (10 sessions) Positive Psychology Interaction Group Program, which was prepared by the researchers based on the positive psychology approach, was applied only to the experimental group. Paired sample t-tests and Person's correlation coefficient analyses were conducted to analyze the data. Multiple linear regression analysis was used to determine the effect of the program on the hope and anger levels of the elderly.

Results: Statistically significant differences were found between the post-test scores of the experimental and control groups $(p<.05)$. The applied Positive Psychology Interaction Group Program increased the hope levels of the elderly individuals participating in the experimental group and decreased their anger levels.

Conclusion: These findings are important for building positive psychology-focused practice in experimental research to improve the lives of elderly people.

Keywords: Anger; Aged; Hope; Psychology, Positive 


\section{INTRODUCTION}

The increasing elderly population around the world has caused a demographic transformation. Aging is on the agenda of health and social policies and has become a global topic of discussion (1). This social change has brought about a new social structure. New concepts, such as healthy aging, active aging, successful aging, and aging in place have recently emerged (2).

Old age is a natural process in which health and social problems are more common than in other age groups. This period, which is the last phase of life, not only affects all areas of an individual's life, but also causes psychological changes (3-4). Elderly individuals today tend to live more socially active lives (5). Therefore, it is important to develop interventions that can sustain the talents and resources of the elderly and prevent or delay physical, cognitive, and emotional decline (6).

In recent years, positive psychology (PP), which has focused on human happiness and well-being, has stimulated hope in individuals with features such as making human life meaningful, increasing enjoyment of life, and working with skills and capacities instead of psychopathology (7-8). In this context, the Positive Psychology Interaction Group Program has been implemented with an expectation of positive effects on the emotional states of elderly individuals, and to develop positive self-perception, life satisfaction, effective communication, and stress coping skills. Studies have reported that PP-focused practices increase individuals' psychological well-being, life satisfaction, and positive affect $(6,9)$.

Hope, which is one of the most important emotions in a person's life journey, is defined as "the emotional belief of individuals about the possibility of positive results about events and situations in their life." Hope plays an important role in human mental health. It prevents the psychological breakdown of the person against life difficulties by giving meaning to life. Joy, happiness, and reduced fear and stress help individuals improve their decision-making power and social participation. Hope contributes to a happier life by generating positive thinking, talent, and courage (10). Charles Richard Snyder, working on Forgiveness and Hope Theo$r y$, is one of the founders of PP. Synder considers hope to be a cognitive ability. Snyder's theory consists of three main components: goals (approaching life with purpose), path (finding different ways to achieve life goals) and means (changeable motivation to achieve life goals). In other words, with hope, an individual has a purpose, believes that there are ways to achieve that purpose, and that they can walk on these paths (11).

Recently, nearly no experimental studies have been conducted on the effect of PP on anger and hope in elderly people. To fill this gap in extant literature, the present study aimed to examine the effect of the Positive Psychology Interaction Group Program on the anger and hope levels of elderly individuals. The program aimed to develop positive self-perception, life satisfaction, effective communication, stress coping skills, and socialization in the elderly.

\section{MATERIALS AND METHOD}

\section{Sample}

The sample comprised 32 individuals aged 65 years and above living in Darülaceze, an institution affiliated with the Ministry of Family, Labor and Social Services. The exclusion criteria were as follows: dementia and delirium, permanent psychiatric disorder with continuing treatment, and inability to read and answer the scales. Those who met the inclusion criteria and gave written consent to participate were randomly placed in the experimental $(n=16)$ and control $(n=16)$ groups.

\section{Measurement Instruments}

All measurement tools were administered both before (pre-test) and after (post-test) the implementa- 
tion of the program.

The Sociodemographic Information Form prepared by the researchers was filled using face-toface interviews. It included information such as gender, age, marital status, number of children, physical/mental illness, and employment status.

Trait Hope Scale (THS) was developed by Snyder et al. (11) and adapted to Turkish by Tarhan and Bacanlı (12) The scale consists of 12 items and two sub-dimensions. The sub-dimensions named "The Pathway" and "Agency" are measured with four items each. The Cronbach's alpha coefficient of the scale was .837 and the KMO value was .862. Higher scores indicate higher levels of trait hope.

State-Trait Anger Scale (STAS) was developed by Spielberger et al. (13) and adapted to Turkish by Ozer (14) The scale uses a four-point Likert rating. It comprises 34 items and includes Trait Anger (10 items) and Anger Expression Style (24 items) subscales. The Anger Expression Style subscale comprises three sub-scales: Controlled Anger (anger/ control, 8 items), Externalized Anger-Out (anger/ external, 8 items), and Internalized Anger (anger/internal, 8 items). The total score ranges from 24-96. Cronbach's alpha values are: .79 (Trait Anger), .84 (Controlled Anger), .78 (Expressed Anger), and .62 (Suppressed Anger) (15).

\section{Data Analysis}

The statistical analyses were performed using the SPSS version 25.0. The data were first examined for normality. All scales showed normal distribution in the control of Kurtosis-Skewness values with the values on all scales and subscales ranging from -2 to +2 . A $95 \%$ level of confidence was used. Paired sample t-tests were used to compare the two parametric groups. The relationships between the scales were tested using Pearson's correlation analysis. Multiple linear regression analysis was used to determine the effect of the independent variable on the dependent variables.

\section{Positive Psychology Interaction Group Program}

This program was derived by using PP resources in the literature (16-20). The experimental group attended the research program twice a week, with a total of 10 sessions of 50 minutes each. Together with the group members, the rules of the interaction group were determined, and decisions were made about continuity, confidentiality, and practices. The program consists of five stages:

1. Awareness Study on Positive Psychology, Active Aging, and Quality of Life (2 Sessions). It aims at improving the elderly individuals' knowledge of the physical, emotional, cognitive, and social changes brought about by the aging process, and to enable them to acquire the necessary knowledge and skills to improve their quality of life and lead a more active and independent life.

\section{Self-Recognition, Awareness, Self-Compas-} sion, and Empathy (2 Sessions). It aims to enable the participants to discover their strengths and develop their application skills in daily life. The sessions aim at improving integration of emotions that are difficult to accept.

\section{Developing Stress Management Strategies} and Anger Management (2 Sessions). The aims of this phase are to enable group members to accept their judgments that cause negative emotions and to reduce the negative impact of events through positive reevaluation. Interactions aimed at enabling participants to develop awareness of situations that reveal anger in them and their subsequent reactions. Activities included asking the group members to think about the last moment they were angry and remember how they felt.

\section{Communication Skills and Relationship Man-} agement (2 Sessions). It aims to improve participants' awareness about effective listening, empathic approach, developing satisfactory relationships, and being thankful and accepting. Additionally, it aims to develop individuals' skills to recognize their emotions and to express them verbally and non-verbally. 
5. Values and Life Satisfaction (2 Sessions). The participants learned how to recognize their feelings in the here and now, reveal positive emotions in their daily experiences, maintain pleasant moments, and develop feelings of gratitude. The group members shared their thoughts about the acceptance of their judgments, their painful emotions, and the appro- priateness of the decisions made by them towards their life goals.

\section{RESULTS}

As seen in Table 1, 37.5\% of the research group were $65-69$ years old, $62.5 \%$ were $70-80$ years old; $25.0 \%$

Table 1. Descriptive Statistics of Sample Demographics

\begin{tabular}{|c|c|c|c|c|c|}
\hline & & \multicolumn{2}{|c|}{ Research Group } & \multicolumn{2}{|c|}{ Comparison Group } \\
\hline & & $f$ & $\%$ & f & $\%$ \\
\hline \multirow{3}{*}{ Age } & $65-69$ & 6 & 37.5 & 13 & 81.3 \\
\hline & $70-80$ & 10 & 62.5 & 3 & 18.8 \\
\hline & Total & 16 & 100.0 & 16 & 100.0 \\
\hline \multirow{3}{*}{ Gender } & Female & 4 & 25.0 & 6 & 37.5 \\
\hline & Male & 12 & 75.0 & 10 & 62.5 \\
\hline & Total & 16 & 100.0 & 16 & 100.0 \\
\hline Neighborhood & Nursing home & 16 & 100.0 & 16 & 100.0 \\
\hline \multirow{4}{*}{ Places lived while growing up } & Village & 3 & 18.8 & 3 & 18.8 \\
\hline & City & 13 & 81.3 & 12 & 75.0 \\
\hline & Town & 0 & 0.0 & 1 & 6.3 \\
\hline & Total & 16 & 100.0 & 16 & 100.0 \\
\hline \multirow{5}{*}{ Marital status } & Single & 9 & 56.3 & 10 & 62.5 \\
\hline & Married & 2 & 12.5 & 0 & 0.0 \\
\hline & Divorced & 1 & 6.3 & 5 & 31.3 \\
\hline & Widowed & 4 & 25.0 & 1 & 6.3 \\
\hline & Total & 16 & 100.0 & 16 & 100.0 \\
\hline \multirow{4}{*}{ Education } & Literate & 1 & 6.3 & 1 & 6.3 \\
\hline & Primary School & 10 & 62.5 & 12 & 75.0 \\
\hline & High school & 5 & 31.3 & 2 & 12.5 \\
\hline & Total & 16 & 100.0 & 15 & 93.8 \\
\hline \multirow{4}{*}{ Employment } & Unemployed & 7 & 43.8 & 9 & 56.3 \\
\hline & Employed & 2 & 12.5 & 0 & 0 \\
\hline & Retired & 6 & 37.5 & 3 & 18.8 \\
\hline & Total & 15 & 93.8 & 12 & 75.0 \\
\hline \multicolumn{2}{|l|}{ Missing } & 1 & 6.3 & 4 & 25.0 \\
\hline \multicolumn{2}{|l|}{ Total } & 16 & 100.0 & 16 & 100.0 \\
\hline \multirow{3}{*}{ Cigarette smoking } & Yes & 3 & 18.8 & 7 & 43.8 \\
\hline & No & 12 & 75.0 & 9 & 56.3 \\
\hline & Total & 15 & 93.8 & 16 & 100.0 \\
\hline \multicolumn{2}{|l|}{ Missing } & 1 & 6.3 & 14 & 87.5 \\
\hline \multicolumn{2}{|l|}{ Total } & 16 & 100.0 & 16 & 100.0 \\
\hline
\end{tabular}


were women; $100.0 \%$ lived in a nursing home; $18.8 \%$ grew up in the village, $81.3 \%$ grew up in the city; $56.3 \%$ were single, $12.5 \%$ were married, $6.3 \%$ were divorced, $25.0 \%$ were widowed; $6.3 \%$ were literate, $62.5 \%$ were primary school graduates, $31.3 \%$ were high school graduates; $43.8 \%$ were unemployed, $12.5 \%$ were working, $37.5 \%$ were retired; $18.8 \%$ were smokers, $75.0 \%$ were non-smokers.

81.3\% of the comparison group were 65-69 years old, $18.8 \%$ were between $70-80$ years old; $37.5 \%$ were women; $100.0 \%$ lived in a nursing home; $62.5 \%$ were single, $31.3 \%$ were divorced; $6.3 \%$ were literate, $75.0 \%$ were primary school graduates, $12.5 \%$ were high school graduates; $56.3 \%$ were unemployed, $18.8 \%$ were retired; $43.8 \%$ were smokers, $56.3 \%$ were non-smokers.

Based on the findings, the average score on the Inner Anger sub-dimension is 2.01 ( $S D=0.64)$, the average on the External Anger sub-dimension is $1.77(\mathrm{SD}=0.63)$, and the average on the Anger Control sub-dimension is $3.14(\mathrm{SD}=0.65)$. Additionally, the average scores on Trait Hope scale, Agency subscale, and Pathway scale are 6.19 (SD=1.29), 5.91 $(\mathrm{SD}=1.67)$, and $6.47(\mathrm{SD}=1.39)$, respectively. The results there was no significant difference between the pre- and post-test scores of the research group on the Internal Anger sub-dimension ( $p>0.05$ ).
As can be seen from Table 2, there was a significant difference between the pre- and post-test scores of the research group on the External Anger sub-dimension $(p<.05)$. The pre-test score was higher than the post-test score. In contrast, no significant difference was found between the pre- and post-test scores of the comparison group on the External Anger sub-dimension ( $p>0.05$ ).

In Table 3, the difference between the pre- and post-test scores of the research group on the Anger Control sub-dimension was found as significant $(p<.05)$. The average post-test score on the Anger Control sub-dimension was significantly higher than the average pretest score. In contrast, there was no significant difference between the pre- and posttest scores of the comparison group on the Anger Control sub-dimension ( $p>0.05)$.

As can be seen from Table 4, the pre-test and post-test scores of the research group on the Trait Hope Scale differed significantly $(p<.05)$. The average post-test score was higher than the average pretest score. In contrast, there was no significant difference between the pre- and post-test scores of the comparison group on the Trait Hope Scale ( $p>0.05)$.

As can be seen from Table 5, the difference between the pre- and post-test scores of the research

Table 2. Results of Paired Sample t-test between the Pre-Test and Post-Test Averages of External Anger Sub-Scales

\begin{tabular}{|c|c|c|c|c|c|c|c|c|}
\hline & & Mean & $\mathbf{N}$ & SD & SE & $t$ & df & $p$ \\
\hline \multirow{2}{*}{ Research Group } & Pre-test & 1.9252 & 16 & 0.72437 & 0.18109 & 2.253 & 15 & 0.040 \\
\hline & Post-test & 1.4453 & 16 & 0.29215 & 0.07304 & & & \\
\hline \multirow{2}{*}{ Comparison Group } & Pre-test & 1.7813 & 16 & 0.63819 & 0.15955 & -1.168 & 15 & 0.261 \\
\hline & Post-test & 1.9375 & 16 & 0.70267 & 0.17567 & & & \\
\hline
\end{tabular}

Standard Deviation (SD), Standard Error (SE) 
Table 3. Results of Paired Sample t-test between the Pre-Test and Post-Test Averages of the Anger Control Sub-Dimension

\begin{tabular}{|l|l|l|l|l|l|l|l|l|}
\hline \multicolumn{2}{|c|}{} & Mean & N & SD & SE & t & df & P \\
\hline \multirow{2}{*}{ Research Group } & Pre-test & 2.8817 & 16 & 0.67558 & 0.16890 & -2.388 & 15 & 0.031 \\
\cline { 2 - 9 } & Post-test & 3.2813 & 16 & 0.47544 & 0.11886 & & \\
\hline \multirow{2}{*}{ Comparison Group } & Pre-test & 3.1250 & 16 & 0.69821 & 0.17455 & -0.877 & 15 & 0.395 \\
\cline { 2 - 9 } & Post-test & 3.2734 & 16 & 0.69405 & 0.17351 & & & \\
\hline
\end{tabular}

Standard Deviation (SD), Standard Error (SE)

Table 4. Results of Paired Sample t-test between the Pre-test and Post-test Averages of the Trait Hope Scale

\begin{tabular}{|l|c|c|c|c|c|c|c|c|}
\hline \multicolumn{2}{|c}{} & Mean & N & SD & SE & t & df & P \\
\hline \multirow{2}{*}{ Research Group } & Pre-test & 6.2500 & 16 & 1.19111 & 0.29778 & -2.351 & 15 & 0.033 \\
\cline { 2 - 9 } & Post-test & 7.0625 & 16 & 0.55715 & 0.13929 & & \\
\hline \multirow{2}{*}{ Comparison Group } & Pre-test & 5.6823 & 16 & 1.51259 & 0.37815 & -0.188 & 15 & 0.853 \\
\cline { 2 - 9 } & Post-test & 5.7708 & 16 & 1.30650 & 0.32663 & & & \\
\hline
\end{tabular}

Standard Deviation (SD), Standard Error (SE)

Table 5. Paired Sample t-test between the Pre-Test and Post-Test Averages of the Agency Subscale

\begin{tabular}{|l|c|c|c|c|c|c|c|c|}
\hline \multicolumn{2}{|c|}{} & Mean & N & SD & SE & t & df & p \\
\hline \multirow{2}{*}{ Research Group } & Pre-test & 6.3594 & 16 & 1.19013 & 0.29753 & -2.687 & 15 & 0.017 \\
\cline { 2 - 9 } & Post-test & 7.1719 & 16 & 0.70545 & 0.17636 & & \\
\hline Comparison Group & Pre-test & 6.0990 & 16 & 1.80078 & 0.45019 & -0.383 & 15 & 0.707 \\
\cline { 2 - 9 } & Post-test & 6.2448 & 16 & 1.48899 & 0.37225 & & & \\
\hline
\end{tabular}

Standard Deviation (SD), Standard Error (SE) 
group on the Agency sub-dimension was significant $(p<.05)$. The average post-test score was higher than the average pre-test scores. On the other hand, there was no significant difference between the preand post-test scores of the comparison group on the Agency sub-dimension ( $p>0.05$ ). Additionally, there was a significant difference between the preand post-test scores of the research group on the Pathway sub-dimension ( $p>0.05$ ). In contrast, there was no significant difference between the pre- and post-test averages of the comparison group on the Pathway sub-dimension ( $p>0.05)$.

\section{DISCUSSION}

In this study, the effect of the Positive Psychology Interaction Group Program, designed for elderly individuals, on the anger and hope levels of the elderly was examined. As the levels of hope and anger in the elderly are important factors affecting their quality of life, many studies have been conducted on this subject (21-24). The results demonstrated a statistically significant increase in hope levels and a decrease in anger levels in the elderly individuals participating in the Positive Psychology Interaction Group Program compared to those who did not participate in this program.

The first finding of this study is that there was a significant increase in the hope level and its subcomponents (Alternative Thought/Agency) in the intervention group as compared to the control group. Previous studies have reported inconsistent results in terms of the hope levels of the elderly. Antoine et al. (21) implemented a six-week multi-dimensional PP intervention. In their study to determine the effects on process variables, including anxiety, depression, psychological distress, awareness, and emotion regulation, it was determined that trait anxiety, depressive symptoms, and psychological distress levels significantly decreased in the intervention group as compared to the control group.

Positive psychology interventions have been ex- perimentally tested in many studies, but only a few studies have addressed the effects of such practices in older participants. One such study by Proyer et al. (25) (2014) examined the long-term effects of PP and placebo-controlled interventions on well-being and depression in individuals aged 50-79 years. It was found that PP interventions caused an increase in the happiness level of the participants and decreased depressive symptoms. Another systematic review supporting these findings reports that PP interventions have positive effects on elderly health (4) Further, a randomized controlled study by $\mathrm{Wu}$ and Koo (24) on 103 elderly patients with mild to moderate dementia showed that hope, life satisfaction, and mental well-being can be significantly improved with a 6-week mental recall intervention.

Further, it was found that the difference between the mean scores of Anger Control and External Anger in the research group was statistically significant. There was a significant increase in the Anger Control level of the intervention group compared to the control group, and a statistically significant decrease in the level of External Anger $(p<.05)$. In a study evaluating the effects of PP interventions on emotions and emotion regulation changes with a six-week self-help program, it was found that compared to the control group, participants in the intervention group showed significant improvements from pre-test to post-test in variables such as anxiety, depression, and psychological distress (21). Emotion regulation strategies greatly affect people's responses to life events and their self-control. PP interventions are effective in developing conscious cognitive coping strategies (23). In this context, PP interventions are thought to have an enhancer function in anger control and expressing emotions.

Positive psychology interventions allow individuals to fully express their potential by helping them develop coping strategies, flexibility, optimism, emotion regulation, and self-efficacy (6). The skills acquired in the domains of life satisfaction, hap- 
piness, positive emotions, coping with stress, and gratitude provide an advantage for the educational and clinical environment $(4,6)$.

Dickens (18) analyzed the effects of gratitude interventions by synthesizing the findings of 38 studies and using meta-analytical techniques. The results showed that gratitude interventions can lead to improvements in a wide range of outcomes, including happiness. In another study in which the Positive Awareness Program (PMP) was applied, welfare criteria such as gratitude, self-compassion, self-efficacy, meaning, and autonomy were tested. The post-test measurements of the participants in the experimental condition showed significant improvements in all dependent variables compared to the pre-test results, and the post-test results were also found to be significantly higher than in the control group (19). These positive results showed that PP interventions are effective in increasing well-being and other positive variables.

Walsh et al. (20), who examined the effect of PP applications on mental health through a systematic review, reported that PP application was proposed as a flexible model that can be applied to different patient groups as well as other treatment groups. More research is needed to determine whether PP application is acceptable and applicable for use in different patient groups and settings.

\section{REFERENCES}

1. Karahan FŞ, Hamarta E. Effect Of Chronic Diseases and Polypharmacy on Death Anxiety And Anxiety in Geriatric Patients. Aegean Medical Sciences Journal, 2019; 2(1): 8-13. (in Turkish) (DOI: https://doi.org/10.33713/ egetbd.463608)

2. World Health Organization. (2017). Global strategy and action plan on ageing and health [e-book] NIH Publication, 2017 [Internet]. Available from: https:// www.who.int/ageing/global-strategy/en/ Accessed: 15.08.2020.

\section{CONCLUSION AND RECOMMENDATIONS}

Despite the promising results of this study, which should be considered as a pilot study, the study has some limitations. The first limitation is the lack of follow-up evaluations. Second, the study was conducted only with elderly individuals living in an institution and in a specific area. Finally, considering that the participants consisted of only literate and educated people, the data obtained within the scope of the research are limited to the qualities measured by the scales used. In line with the literature, the positive changes in the intervention group in which PP studies were applied show that elderly individuals allow themselves to evaluate their psychological resources.

\section{Compliance with ethical standards}

All procedures performed in this study complied with the ethical standards of the national research committee and the 1964 Helsinki Declaration and its subsequent amendments or comparable ethical standards.

\section{Conflict of Interest}

The authors have no conflicts of interest to disclose.

\section{Informed Consent}

Informed consent was obtained from all participants.

3. Akgül H, Yeşilyaprak B. The Effect of Decreasing Loneliness Psychoeducation Program on The Level of Loneliness Among Elderly. OPUS-International Social Research Journal 2018; 8(14): 11-52. (DOI: https://doi. org/10.26466/opus.40133132) (in Turkish)

4. Sutipan P, Intarakamhang U, Macaskill A. The Impact Of Positive Psychological Interventions on Well-Being in Healthy Elderly People. Journal of Happiness Studies. 2017; 18(1): 269-291. (DOI: https://doi.org/10.1007/ s10902-015-9711-z)

5. Douka S, Zilidou VI, Lilou O, Manou, V. Traditional Dan- 
ce Improves The Physical Fitness And Well-Being of The Elderly. Frontiers in Aging Neuroscience 2019; 11: 75. (DOI: https://doi.org/10.3389/fnagi.2019.00075)

6. Cantarella A, Borella E, Marigo C, De Beni R. Benefits of Well-Being Training in Healthy Older Adults. Appl Psychol Health Well Being. 2017 Nov;9(3):261-284. (PMID: 28877404).

7. Eryılmaz A. Positive Psychotherapies. Current Approaches in Psychiatry 2017; 9(3): 346-362. (in Turkish) (DOI: https://doi.org/10.18863/pgy.288667)

8. ME Seligman, Flourish: A Visionary New Understanding of Happiness and Well-Being (1st Free Press hardcover ed.). Free Press, New York, NY, 2011.

9. Dilmaç B, Kocaman EN. Investigation of The Relationship Between Hope and The Psychological Well-Being in A Group Of Adults in Terms of Different Variables. Social Sciences and Education Research Review, 2019; 6(1): 6-29.

10. Tarhan, N. Psychology of Emotions. Timaş Publicatons, Istanbul, 2012.(in Turkish)

11. Snyder CR. Hope Theory Rainbows in the Mind. Psychol Inguiry 2002, 13:249-75

12. Tarhan S, Bacanlı H. Turkish Adaptation of Trait Hope Scale: Reliability and Validity Study. The Journal of Happiness \& Well-Being, 2015; 3(1): 1-14. (in Turkish).

13. Spielberger CD. Assessment of State and Trait Anxiety: Conceptual and Methodological Issues. Southern Psychologist, 1985; 2(4): 6-16.

14. Özer AK. Trait Anger and Anger as an Expression Scales Preliminary Study. Turkish Psychology Journal, 1994; 9(31): 26-35. (in Turkish).

15. I Savaşır, NH Şahin, Bilişsel Davranışçı Terapilerde Değerlendirme: Sık Kullanılan Ölçekler, Ankara: Türk Psikologlar Derneği Yayınları, 1997.

16. Celano CM, Beale EE, Mastromauro CA, et al. Psychological interventions to reduce suicidality in high-risk patients with major depression: a randomized controlled trial. Psychol Med. 2017 Apr;47(5):810-821. 3. (PMID: 27876105).
17. Huffman JC, Beale EE, Celano CM, et al. Effects of Optimism and Gratitude on Physical Activity, Biomarkers, and Readmissions After an Acute Coronary Syndrome: The Gratitude Research in Acute Coronary Events Study. Circ Cardiovasc Qual Outcomes. 2016 Jan;9(1):55-63. (PMID: 26646818).

18. Dickens LR. Using Gratitude to Promote Positive Change: A Series of Meta-Analyses Investigating the Effectiveness of Gratitude Interventions, Basic and Applied Social Psychology, 2017; 39(4): 193-208, (DOI: https://doi.org/10.1080/01973533.2017.1323638)

19. Ivtzan I, Young T, Martman J, et al. Integrating Mindfulness into Positive Psychology: A Randomised Controlled Trial of an Online Positive Mindfulness Program. Mindfulness, 2016; 7(6): 1396-1407. (DOI: https://doi. org/10.1007/s12671-016-0581-1)

20. Walsh S, Cassidy M, Priebe S. The application of positive psychotherapy in mental health care: A systematic review. J Clin Psychol. 2017;73(6):638-51. (PMID: 27482845]).

21. Antoine P, Dauvier B, Andreotti E, Congard A, Individual Differences in The Effects of a Positive Psychology Intervention: Applied Psychology. Personality and Individual Differences, 2018; 122: 140-147. (DOI: https://doi.org/10.1016/j.paid.2017.10.024)

22. Gupta S, Singh A. The Study of Resilience and Hope among Elderly People. Indian Journal of Gerontology, 2020; 34(3): 343-352.

23. Hernandez, SC Overholser, JC. A Systematic Review of Interventions For Hope / Despair in Older Adults., Clinical Gerontologist. 2020; pp. 1-15. (in Turkish).

24. Wu LF, Koo M. Randomized controlled trial of a six-week spiritual reminiscence intervention on hope, life satisfaction, and spiritual well-being in elderly with mild and moderate dementia. Int J Geriatr Psychiatry. 2016 Feb;31(2):120-7. (PMID: 25965388).

25. Proyer RT, Gander F, Wellenzohn S, Ruch W. Positive psychology interventions in people aged 50-79 years: long-term effects of placebo-controlled online interventions on well-being and depression. Aging Ment Health. 2014;18(8):997-1005. (PMID: 24712501). 